\title{
Obituary
}

\section{G. J. Minnaert}

Professor M. G. J. Minnaert, director of the observatory at Sonnenborgh, Utrecht, from 1937 to 1963, died on October 26, 1970, at the age of seventyseven.

His career as a solar physicist, the activity for which he is best known to astronomers, did not begin until he was over thirty. He started, in fact, as a botanist, graduating at the University of Ghent, but his wish to understand better the effects of light on plants led him to Leiden before the 1914-18 war to study physics; it was his support for the Flemish movement, especially during the war, that led to his exile in Holland and to his post at the Physics Institute in Utrecht as a solar physicist. Here he worked for some years under Julius, from whom, according to his own testimony, he learnt much in optics and practical physics. Inspired by the techniques of photographic spectrophotometry, which were at that time being developed in Utrecht by Ornstein, Moll and van Cittert, he was one of the first to measure intensity profiles of the Fraunhofer lines in the solar spectrum and to attempt to explain these by theoretical models. In the 1930s, he and his pupils achieved a steady improvement in the methods of photographic spectrophotometry and in our knowledge of Fraunhofer lines and how they are formed. Among many others things, they superseded Rowland's empirical estimates by objective measurements of total absorption; they clarified the role of Doppler effect and damping in Fraunhofer line formation; and they introduced astronomers to the "curve of growth", the curve giving total line strength as a function of the number of absorbing atoms, which in various forms continues to be widely used up to the present day.

In 1940 the last commercial plane to leave Europe for America, before the war finally closed in, carried copies of the Photometric Atlas of the Solar Spectrum by Minnaert and his two pupils, J. Houtgast and G. F. W. Mulders, a publication which is still a standard work of reference. After the war he and his staff used the atlas for the Preliminary Photometric Catalogue of Fraunhofer Lines, $\lambda 3164-\lambda 8770$, followed in 1966 by The Solar Spectrum $2935 \AA-8770 \AA$, in cooperation with C. E. Moore and J. Houtgast. He also published two authoritative and very useful articles in Kuiper's series on the solar system, in Volume I on The Photosphere (1953) and in Volume III on Photometry of the Moon (1961). Mention should be made also of his last book, Practical Work in Elementary Astronomy (1969), a first introduction to many of the practical techniques of optical astronomy which characteristically relies on demonstrations with only the simplest equipment.

A brief summary of his technical publications gives a very inadequate picture of one who, by his enthusiasm and idealism, his modesty and sincerity, his good humour and extraordinarily wide range of interests and abilities, made a profound impression on everyone he met. He was a natural and tireless teacher of astronomy and an equally persistent opponent of popular belief in astrology. Perhaps his best known publication is De Natuurkunde van 't Vrije Veld, of which Volume I-known in English translation under the title
Light and Colour in the Open Air-is a masterpiece of popular science describing the optical phenomena associated with meteorology. He was an excellent linguist and revealed a wide and appreciative acquaintance with European literature in Dichters Over Sterren, a multilingual anthology of poetry dealing with stars and astronomy. $\mathrm{He}$ was a talented musician and at one time he possessed a remarkable collection of musical instruments which he later donated to the University of Utrecht.

He was on the staff of the Utrecht Physical Laboratory and later the Observatory for altogether 44 years; he was director of the Observatory and professor of astronomy from 1937 until his retirement in 1963, and more than any other man was responsible for building up the strong school of astronomy which still flourishes there.

He was a strong supporter of international causes, especially of the International Astronomical Union, and served as chairman of several of its commissions. For many years he was exiled from his native Belgium because of his open advocacy of the Flemish movement and during the Second World War he was one of about a hundred Dutch intellectuals who were imprisoned as hostages by the Nazis under daily threat of execution. Grateful witnesses have testified at first hand to how much he did during this time, by organizing talks and lectures, to preserve the morale and even the sanity of his fellow prisoners.

Among the many honours he received were the Gold Medal of the Royal Astronomical Society and the Bruce Medal of the Astronomical Society of the Pacific.
Announcements

\section{University News}

Professor A. J. Youngson and Professor Denys Hay have been appointed viceprincipals of the University of Edinburgh, in succession to Professor J. W. Crofton and Professor D. Talbot Rice respectively.

Dr R. Goldsmith, University of Nottingham, has been appointed to the chair of physiology at Chelsea College, University of London.

Mr George King, chief scientist of Standard Telecommunication Laboratories Limited, has been appointed visiting professor in telecommunications in the University of Surrey.

\section{Appointments}

Dr J. P. Wild has been appointed chief of the CSIRO Division of Radiophysics, in succession to Dr E. G. Bowen.

Dr J. Morton Boyd has been appointed director of the Nature Conservancy in Scotland, in succession to Dr W. $J$. Eggeling.

Dr V. Armstrong, New Zealand, has been appointed chairman of the executive council of the Commonwealth Agricultural Bureaux, in succession to $\mathbf{M r} \mathbf{W}$. G. Alexander, and $\mathrm{Mr}$ E. S. Kapotwe, Zambia, has been appointed vicechairman.

\section{Miscellaneous}

Sir Martin Ryle has been awarded the
Faraday medal of the Institution of Electrical Engineers for his contribution to the design and engineering of new types of aperture synthesis aerials and associated equipment.

Applications are invited by the trustees of the Lady Tata Memorial Trust for fellowships and scholarships for research on leukaemia, particularly studies of the leukaemogenic viruses in mammals, the epidemiology and natural history of leukaemia and the immunogenic aspects. The awards are available to qualified investigators of any nationality, working in their own institutions or abroad. Further information can be obtained from the Secretary of the (European) Scientific Advisory Committee, Lady Tata Memorial Trust, Chester Beatty Research Institute, Fulham Road, London SW3. 